УДК 621.865 .8

О.Д. Романюк, к.т.н., доцент, oleksandrromaniuk5@gmail.com

Дніпровський державний технічний університет, м. Кам'янське

\title{
ОСНОВНІ ПІДХОДИ ОПТИМІЗАЦЇ̈ МАС ЗУБЧАСТИХ КОЛІС МЕХАНІЧНОЇ ПЕРЕДАЧІ
}

В даній роботі виконаний розширений аналіз впливу основних геометричних параметрів механічної передачі на вибір оптимальної маси зубчастого колеса яка б відповідала маховому моменту маховика на етапі попереднього проектування з метою стабілізаиії кінематичних та динамічних характеристик машинного агрегату без використання додаткових мас.

Ключові слова: механічна передача, маса, зубчасте колесо, проектування.

In this work was performed an extended analysis of the effect of the main geometric parameters of the mechanical transmission on the selection of the optimum gear's mass. It is corresponded to the flywheel moment of the flywheel in the preliminary design stage in order to stabilize the kinematic and dynamic characteristics of the machine assembly without the use of additional masses.

Keywords: mechanical transmission, mass, cogwheel (gearwheel), design.

\section{Постановка проблеми}

В процесі проектування схеми приводу виконавчого органу машини використовують стандартні механічні передачі, серед яких найбільш поширені редуктори з циліндричними зубчастими колесами. Але, враховуючи той факт, що в режимі усталеного руху кінематичні та силові характеристики ланок механізму являються періодичними функціями в наслідок амплітудних коливань передаточної функції механізму, виникає необхідність зменшення амплітуди коливань швидкості ланки зведення. На основі цього задачу оптимізації кінематичних та силових характеристик приводу виконавчого органу машини вирішують різними способами, але найбільш поширений полягає в використанні додаткових махових мас [1,2,3,4]. Використання маховика дає можливість суттєво знизити амплітуду коливань швидкості ланки зведення, так як обумовлює збільшення зведеного моменту інерції механізму. Недоліком встановлення маховика є додаткова маса, що збільшує вагу механізму та його інерційність. Тому, щоб уникнути відповідних недоліків додаткових махових мас в процесі синтезу схеми приводу виконавчого органу машини необхідно підбирати такий стандартний редуктор, маховий момент зубчастих коліс якого відповідав би додатковій маховій масі. Але на практиці підібрати відповідний редуктор практично не можливо. Більш доцільніше проектувати нові передаточні механізми моменти інерції обертальних мас яких могли б виконувати функцію маховика.

Аналіз останніх досліджень та публікацій

Основні підходи розв'язування задач проектування передаточних механізмів на основі оптимізації їх кінематичних та силових характеричтик розглядалися в роботах $[5,6,7,8]$, але тільки в випадках розглядаючи загальні елементи схеми приводу без урахування обертальних мас безпосередньо елементів схеми приводу виконавчого органу машини.

При вирішенні поставленої проблеми необхідно підібрати на стадії проектування відповідну масу зубчатого колеса механічної передачі, яка б відповідала маховому моменту маховика [9]. Враховуючи, той факт, що маховий момент обертальної маси розташованої на швидкохідному валу передачі менший в $i^{2}$ раз по відношенню до маси на тихохідному валу поставлену задачу можна розв'язати використовуючи шестерню швидкохідної ступені як маховик, що суттєво зменшуємо загальну вагу машинного агрегату [10]. Задачі проектування зубчастих механізмів з урахуванням оптимізації кінематичних та силових характеристик приводу виконавчого органу машинного агрегату являються багато критеріальними, так як виникає необхідність враховувати взаємно залежні параметри $[9,10]$. 


\section{Формулювання мети дослідження}

Виходячи із умови взаємодії між деталями зубчастої передачі, яка виражаються рівняннями зв'язку, що описують умови функціонування передачі, то при проектуванні ці рівняння утворюють систему з відповідною кількістю невідомих. Але особливість проектування зубчастої передачі при умові іiї оптимізації полягає в тому, що кількість невідомих величин проектування набагато більше ніж рівнянь зв'язку, що суттєво ускладнює і без того багатоваріантність задачі. Тому ставиться задача зменшити число невідомих, використовуючи інші міркування, чи допускати їх зміну в деяких межах, а також встановити вплив відповідних параметрів на характер зміни маси зубчастого колеса в процесі його проектування.

Враховуючи, що згідно роботам $[9,10]$ маса зубчатого колеса механічної передачі залежить від шістки основних перемінних величин проектування: передаточного відношення редуктора $i$; нормального модуля зачеплення $m_{n}$; кількості зубів шестерні $z_{1}$; куту нахилу зуба $\beta$; коефіцієнта ширини зубчатого колеса по міжосьовій відстані $\psi_{b a}$; питомої ваги матеріалу зубчатого колеса $\rho$, встановимо можливість зменшити кількість перемінних величин, а також характер впливу відповідних параметрів на масу зубчастого колеса при його оптимізації.

Вибираємо наступні обмеження для перемінних величин проектування.

1. Розглянемо одноступінчату циліндричну зубчасту передачу для якої передаточне відношення згідно стандарту повинне задовольняти умові:

$$
1 \leq i \leq 6,3 \text {. }
$$

2. Нормальний модуль зачеплення зубчастої передачі, який вибираємо тільки з першого ряду відповідного стандартного, повинний задовольняти умові:

$$
1,0 \leq m_{n} \leq 10,0 \text {. }
$$

3. Розглянемо нормальну не кореговану зубчасту передачу, для якої мінімальна величина зубів шестерні повинна задовольняти умові:

$$
z_{\min } \geq 17 .
$$

4. Розглядаємо прямозубу передачу ( $\beta=0^{\circ}$ ) та передачу з косим зубом, кут нахилу якої повинен задовольняти умові:

$$
8^{\circ} \leq \beta \leq 15^{\circ} .
$$

5. Коефіцієнт ширини вінця зубчатого колеса по міжосьовій відстані згідно рекомендацій, назначаємо з умови:

для прямозубої передачі

$$
0,125 \leq \psi_{b a} \leq 0,25
$$

для передачі з косим зубом

$$
0,25 \leq \psi_{b a} \leq 0,5 .
$$

6. Питому вагу матеріалу зубчатих коліс в даному випадку можемо розглядати, як постійну величину, враховуючи що зубчасті колеса будуть виготовлятися із одного матеріалу. Для сталі 40X, 30XН, 40ХН, з яких в основному виготовляють зубчасті колеса, питома вага $\rho=7820 \kappa \Gamma / \mathrm{M}^{3}$.

\section{Виклад основного матеріалу}

Математична модель зубчастої передачі, яка $є$ елементом математичної моделі машинного агрегату представлена на рис.1. коліс [9],

На основі математичної моделі було отримано рівняння для визначення маси зубчастих

$$
\begin{aligned}
& m_{1}=A\left(1+i_{12}\right) z_{1}^{3}, \\
& m_{2}=A\left(1+\frac{1}{i_{12}}\right) z_{2}^{3},
\end{aligned}
$$


де $A-$ коефіцієнт маси зубчатих коліс

$$
A=\frac{1}{8} \pi \rho \psi_{b a}\left(\frac{m_{n}}{\cos \beta}\right)^{3} .
$$

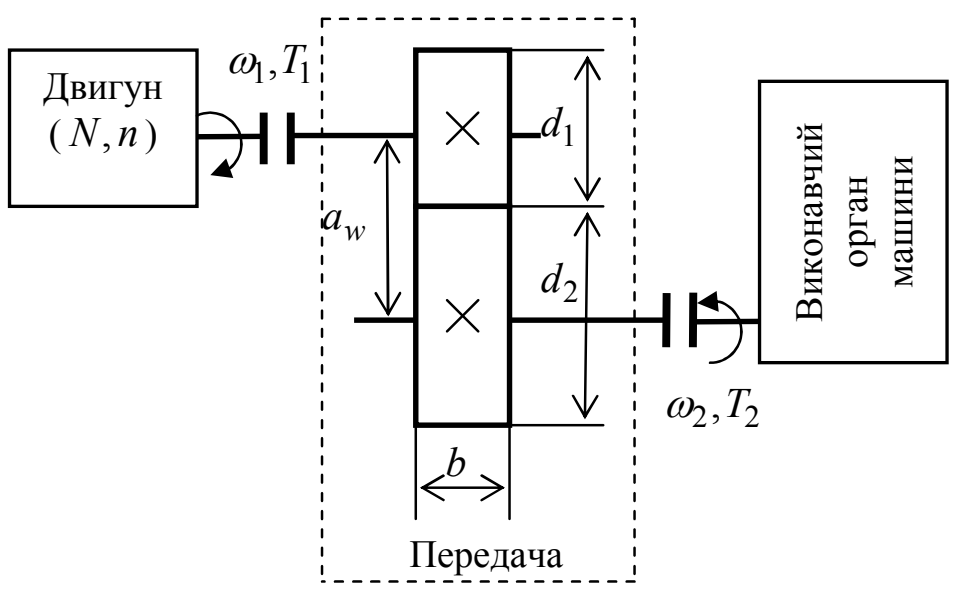

Рис. 1. Математична модель зубчастої передачі

В роботі [10] розглянуто відношення маси колеса до маси шестерні зубчастої передачі

3 урахуванням, що

$$
\frac{m_{2}}{m_{1}}=\frac{z_{2}^{3}}{i z_{1}^{3}},
$$

$$
i=\frac{z_{2}}{z_{1}}
$$

було отримано залежність

$$
m_{2}=i^{2} m_{1}
$$

яка дає можливість в процесі проектування при заданому передаточному відношенні розглядати масову характеристику тільки одного із зубчастих коліс.

3 метою спрощення процесу оптимізації підбору необхідної маси зубчастих коліс на етапі початкового проектування, враховуючи багатоваріантність даної інженерної задачі, проведемо більш розширений аналіз взаємозалежних параметрів передачі, з цілю зменшення їх кількості.

Аналіз результатів дослідження (рис. 2) вказує на те, що коефіцієнт відношення $A_{\max }$ до $A_{\min }$ практично є постійною величиною для любого передаточного відношення

$$
k=\frac{A_{\max }}{A_{\min }} \approx 2,0,
$$

як для прямозубих, так і для передач з косим зубом.

На рис. $2 a$ побудовані графіки залежності $A$ від $\psi_{a b}$ для прямозубої передачі, а на рис. 26 для передачі з косим зубом. Пряма 1 відповідає величині модуля $m_{n}=1,5$,мм, 2 відповідно $m_{n}=2,0$ мм, 3 відповідно $m_{n}=2,5$ мм, 4 відповідно $m_{n}=3,0$ мм.

Враховуючи, що маса зубчастих коліс $є$ функцією передаточного відношення та кількості зубів, при умові, що коефіцієнт маси зубчастих коліс вважаємо деякою постійною величиною отримаємо залежності $m$ від $A$ (рис. 3). 


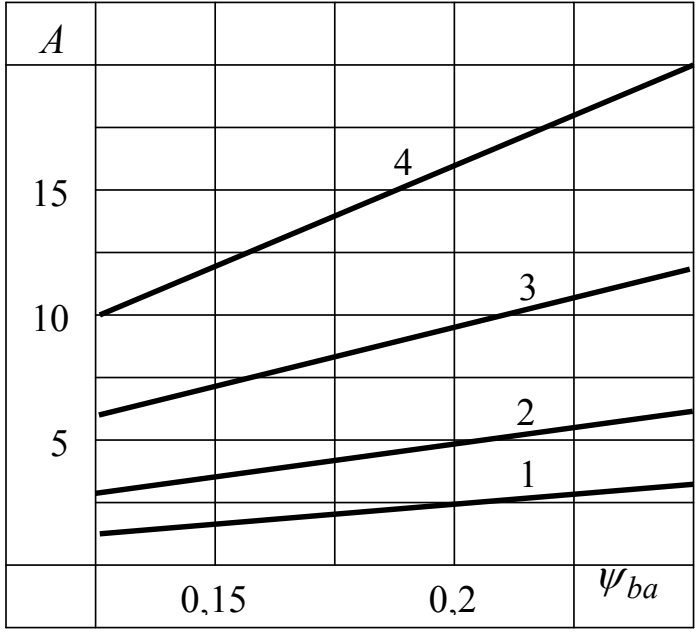

a)

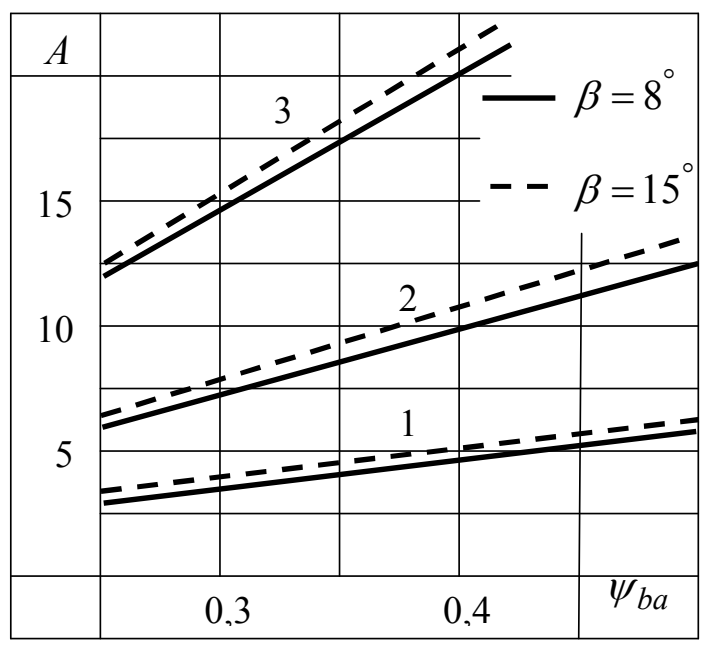

б)

Puc.2. Графіки залежності $A \times 10^{6}$, кг від $\psi_{a b}$

\begin{tabular}{|c|c|c|c|c|c|c|c|c|c|c|c|c|}
\hline \multicolumn{13}{|c|}{$m_{1}$} \\
\hline \multicolumn{13}{|c|}{3} \\
\hline \multicolumn{13}{|l|}{2,8} \\
\hline 2,6 & & & & & & 9 & & & & 4 & & \\
\hline 2,4 & & & & & & & & & 3 & & & \\
\hline \multicolumn{13}{|l|}{2,2} \\
\hline \multicolumn{13}{|l|}{2,0} \\
\hline \multicolumn{13}{|l|}{1,8} \\
\hline \multicolumn{13}{|l|}{1,6} \\
\hline 1,4 & & & 1 & & & & & & & & 5,6 & \\
\hline \multicolumn{13}{|l|}{1,2} \\
\hline \multicolumn{13}{|l|}{1,0} \\
\hline 0,8 & & & & & & & & & & & $\gamma_{1}$ & \\
\hline \multicolumn{13}{|l|}{0,6} \\
\hline \multicolumn{13}{|l|}{0,4} \\
\hline \multicolumn{13}{|l|}{0,2} \\
\hline \multicolumn{13}{|l|}{0} \\
\hline 0 & 10 & 20 & 30 & 40 & 50 & 60 & 70 & 80 & 90 & 100 & 110 & $A$ \\
\hline
\end{tabular}

Рис.3. Графіки залежності $m_{1}$, кг від $A \times 10^{6}$, кг

Графіки 1, 2, 3, 4 побудовані для прямозубої циліндричної передачі, а 5, 6, 7, 8 для передачі $з$ косим зубом при умові, що для обох передач $z_{1}=17$ шт. Прямі 1,2 та 5,6 побудовані для мінімальної величини передаточного відношення $i=1,25$, а прямі 3,4 та 7, 8 для максимальної величини передаточного відношення $i=6,3$. Графіки 1, 3, 5, 7 відповідають мінімальній величині коефіцієнту маси зубчастих коліс $A_{\min }$, а 2, 4, 6, 8 відповідають максимальній величині коефіцієнту маси зубчастих коліс $A_{\max }$. Графіки 9, 10 побудовані для прямозубої циліндричної передачі при $z_{1}=30$ шт. та величини передаточного відношення $i=1,25$. Пряма 9 від- 
повідає мінімальній величині коефіцієнту маси зубчастого колеса $A_{\min }$, а 10 відповідає максимальній величині коефіцієнту маси зубчастого колеса $A_{\max }$.

Маса шестерні $m_{1}$ зубчастої передачі згідно графіків рис 3. практично не змінюється для одного і того ж передаточного відношення, не залежно від зміни коефіцієнту ширини вінця зубчатого колеса по міжосьовій відстані та куту нахилу зуба. Крім того, розрахунки показують що, маса зубчастого колеса не суттєво залежить від амплітуди зміни величини коефіцієнту маси зубчастого колеса і відповідні відхилення становлять не більше 0,8-1,2\%. Дана похибка значно менше допустимих відхилень які регламентовані стандартом при проектуванні механічних передач. Відповідно з отриманих результатів, на етапі початкового проектування, вирішуючи задачу оптимізації маси зубчастого колеса параметри $\psi_{a b}$ i $\beta$ можна не підбирати, що обумовлює зниження кількості невідомих в процесі проектування до трьох. Згідно даного висновку основними параметрами проектування залишаються нормальний модуль зачеплення, передаточне відношення передачі та кількість зубів зубчастого колеса. В даному випадку $m_{n}$ може виступати як неявно змінна характеристика яка обумовлює зміну $A$. Таким чином введений автором в роботі [9] коефіцієнт маси зубчастого колеса дає можливість суттєво спростити процес вибору оптимальної маси зубчастого колеса на етапі початкового проектування, яка б відповідала необхідному маховому моменту. Вибір параметрів які були виключені в процесі початкового проектування $m_{n}, \psi_{a b}$ і $\beta$ встановлюються із відповідних залежностей [10] при розрахунку геометричних параметрів передачі.

Характер зміни маси зубчастого колеса від коефіцієнта маси зубчастого колеса згідно графіків рис. 3 суттєво залежить тільки від величини передаточного відношення механізму $i$ та кількості зубів зубчастого колеса $z$. Таким чином кількість змінних параметрів проектування 3 шістьох величин зводиться до двох, що суттєво спрощує розв'язування поставленої задачі. Крім того, як вказують побудовані залежності, змінюючи один із двох параметрів значно може зростати величина маси колеса, що дає можливість витримати чіткі межі інерційності при необхідних габаритних розмірах передачі.

Результати досліджень залежності $m$ від $A$ при відповідній зміні параметрів $i$ та $z$ дають можливість підібрати таку масу зубчастого колеса маховий момент якого забезпечував би стабілізацію кінематичних та динамічних характеристик машинного агрегату.

Обертальна маса механічної передачі в схемі приводу складається не тільки з маси зубчастого колеса, а також маси валу та підшипників. Відповідна маса, яка не враховувалась в даному випадку, в редукторах які передають значні обертальні моменти практично може дорівнювати масі зубчастого колеса. Таким чином подальші дослідження можуть бути направлені на розширення математичної моделі для встановлення оптимальної маси складальної одиниці 3 метою стабілізації кінематичних та динамічних характеристик машинного агрегату.

\section{Висновки}

1. Виконаний розширений аналіз впливу відповідних геометричних параметрів прямозубої та передачі 3 косим зубом на вибір оптимальної маси зубчастого колеса 3 метою стабілізації кінематичних та динамічних характеристик машинного агрегату.

2. Встановлено, що на етапі попереднього проектування зубчастої передачі нормальний модуль зачеплення, коефіцієнт ширини вінця зубчастого колеса по міжосьовій відстані та кут нахилу зуба можуть бути не визначені. Зменшення кількості взаємно залежних параметрів проектування 3 шести до двох значно спрощує вирішення поставленої задачі. Числове значення відповідних параметрів уточнюється на етапі остаточного проектування при розрахунку геометричних параметрів передачі та перевірки передачі на міцність.

3. Суттєва залежність маси зубчастого колеса від передаточного відношення передачі та кількості зубів дає можливість на етапі попереднього проектування при відповідній зміні одного із параметрів (чи двох) оптимально підібрати масу зубчастого колеса яка відповідала необхідному інерційному моменту схеми приводу, що знімає необхідність використання додаткової маси, маховика. 


\section{Список використаної літератури}

1. Геминтерн В.Н., Коган Б.М. Методы оптимального проектирования. М.: Энергия, 1980. $160 \mathrm{c}$.

2. Соболь И.М., Статников Р.Б. Выбор оптимальных параметров в задачах со многими критериями. М.: Дрофа, 2006. - 175 с.

3. Джента Дж. Накопители кинетической енергии. Теория и практика современных маховичных систем. М.: Мир, 1988. -430 с.

4. Метод многокритериальной оптимизации параметров зубчатых механизмов /А.Д. Романюк// Сборник научных трудов Керченского государственного морского технологического университета «Механизация производственных процессов рыбного хозяйства, промышленных и аграрных предприятий. Механика твердого тела»- Выпуск 11 , 2010. - С. 81-85.

5. Определение минимального времени разгона машинного агрегата /А.Д. Романюк// Сборник научных трудов Керченского государственного морского технологического университета и Днепродзержинского государственного технического университета «Механизация производственных процессов рыбного хозяйства, промышленных и аграрных предприятий. Механика твердого тела»- Выпуск 13, 2012. - С. 144-146.

6. Синтез передаточного механизма оптимального по критерию динамичности /А.Д. Романюк// Сборник научных трудов Днепродзержинского государственного технического университета и Керченского государственного морского технологического университета «Механика твердого тела. Механизация производственных процессов рыбного хозяйства, промышленных и аграрных предприятий.» - Выпуск 14, 2013. - С. 20-23.

7. Основные подходы решения задач синтеза передаточных механизмов на основе оптимизации его характеристик / А.Д. Романюк // Сборник научных трудов Днепродзержинского государственного технического университета и Керченского государственного морского технологического университета «Механика твердого тела. Механизация производственных процессов рыбного хозяйства, промышленных и аграрных предприятий.»- Выпуск 14, 2013. - С. 24-26.

8. Оптимизация передаточной функции механизма /А.Д. Романюк, Л.И. Мамаев, А.М. Кабаков, Л.П. Телипко// Материалы XII международной научно-практической конференции «Актуальные научные достижения - 2016» 22-30 июня 2016. Том 11, Технические науки Praha: Publishing House «Education and Science» s.r.o - 2016. - C.14-17.

9. Вибір махових мас ланок передаточних механізмів на основі оптимізації передаточної функції /О.Д. Романюк// Математичне моделювання. - 2015. - № 2(33) - С. 52-54.

10. Оптимізація мас зубчастих коліс механічної передачі на етапі попереднього проектування /О.Д. Романюк// Математичне моделювання. - 2016. - № 2(35) - С. 35-38. 